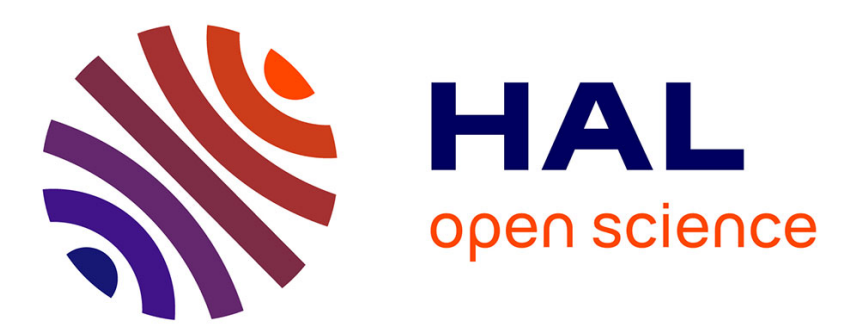

\title{
Pulsed Current-Mode Supply of Dielectric Barrier Discharge Excilamps for the Control of the Radiated Ultraviolet Power
}

\author{
Hubert Piquet, Sounil Bhosle, Rafael Diez, Mikhail V. Erofeev
}

\section{- To cite this version:}

Hubert Piquet, Sounil Bhosle, Rafael Diez, Mikhail V. Erofeev. Pulsed Current-Mode Supply of Dielectric Barrier Discharge Excilamps for the Control of the Radiated Ultraviolet Power. IEEE Transactions on Plasma Science, 2010, vol. 38 ( $\mathrm{n}^{\circ}$ 10), pp. 2531-2538. 10.1109/TPS.2010.2060735 . hal-01412333

\section{HAL Id: hal-01412333 \\ https://hal.science/hal-01412333}

Submitted on 8 Dec 2016

HAL is a multi-disciplinary open access archive for the deposit and dissemination of scientific research documents, whether they are published or not. The documents may come from teaching and research institutions in France or abroad, or from public or private research centers.
L'archive ouverte pluridisciplinaire HAL, est destinée au dépôt et à la diffusion de documents scientifiques de niveau recherche, publiés ou non, émanant des établissements d'enseignement et de recherche français ou étrangers, des laboratoires publics ou privés. 


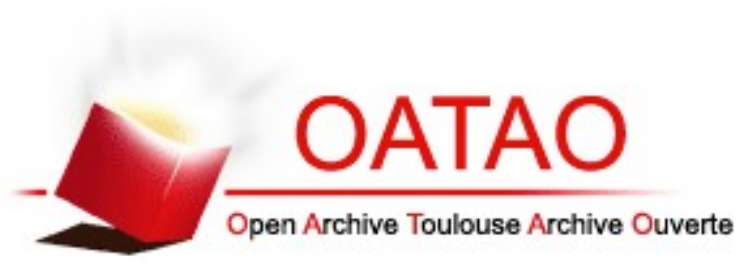

\section{Open Archive Toulouse Archive Ouverte (OATAO)}

OATAO is an open access repository that collects the work of Toulouse researchers and makes it freely available over the web where possible.

This is an author-deposited version published in: http://oatao.univ-toulouse.fr/ Eprints ID: 16730

To link to this article : DOI: $10.1109 /$ TPS.2010.2060735

URL : http://dx.doi.org/10.1109/TPS.2010.2060735

To cite this version: Piquet, Hubert and Bhosle, Sounil and Diez, Rafael and Erofeev, Michael V. Pulsed Current-Mode Supply of Dielectric Barrier Discharge Excilamps for the Control of the Radiated Ultraviolet Power. (2010) IEEE Transactions on Plasma Science, vol. 38 ( $\left.\mathrm{n}^{\circ} 10\right)$. pp. 2531-2538. ISSN 0093-3813

Any correspondence concerning this service should be sent to the repository administrator: staff-oatao@listes-diff.inp-toulouse.fr 


\title{
Pulsed Current-Mode Supply of Dielectric Barrier Discharge Excilamps for the Control of the Radiated Ultraviolet Power
}

\author{
Hubert Piquet, Sounil Bhosle, Member, IEEE, Rafael Diez, and Michael V. Erofeev
}

\begin{abstract}
UV excimer lamps are efficient narrowband sources of $U V$ radiation with applications in various domains. The issue of controlling the UV emission by means of the power supply associated with such lamps favors pulsed current-controlled generators. After having established the previous statements, we propose a dedicated power converter topology which implements the needed performances. The analysis of the degrees of freedom of this structure shows the capability of this pulsed supply to realize the control of both the pulses' current energy and of the mean power transferred to the lamp. Actual experimental realizations and measurement are presented and the feasibility and the performances of the proposed solutions are established.
\end{abstract}

Index Terms-Dielectric barrier discharge (DBD), excilamps, pulsed current-mode supply, UV emission control.

\section{INTRODUCTION}

$\mathbf{E}$ XCILAMPS are electrodischarge sources of incoherent spontaneous UV and VUV radiation, which is emitted due to the decay of excimer and exciplex molecules. They have some distinctions which may be widely used in different fields of science and technology. The main distinguishing feature between the excilamps and traditional mercury lamps, as well as thermal sources of UV radiation, is the emission spectrum; up to $80 \%$ of radiant power may be concentrated in a narrow spectral band of transition of the corresponding molecule (a few nanometers at half maximum). It makes possible to use excilamps in applications where selective effect on complex systems induced by narrow band of UV and VUV radiation is needed. For example, in the stimulation of photobiologi-

H. Piquet is with the Laboratoire Plasma et Conversion d'Energie (LAPLACE) Laboratory, UMR 5213, CNRS-INPT-UPS-Université de Toulouse, 31071 Toulouse, France (e-mail: Hubert.piquet@Laplace.univtlse.fr).

S. Bhosle was with the LAPLACE Laboratory, UMR 5213, CNRS-INPTUPS-Université de Toulouse, 31071 Toulouse, France. He is now with the LED Engineering Development, 31100 Toulouse, France (e-mail: sounil.bhosle@ led-development.fr).

R. Diez was with the LAPLACE Laboratory, UMR 5213, CNRS-INPTUPS-Université de Toulouse, 31071 Toulouse, France. He is now with the Department of Electronics, Pontificia Universidad Javeriana, Bogotá, Colombia (e-mail: rdiez@javeriana.edu.co).

M. V. Erofeev is with the Institute of High Current Electronics, Siberian Branch of Russian Academy of Sciences, Tomsk 634055, Russia (e-mail: michael@loi.hcei.tsc.ru). cal, photochemical, and photophysical processes, such as the inactivation of microorganisms [1], [2], photolytic processing of metal, dielectric and semiconductor layers, surface cleaning and decomposition of harmful organics [3]-[5]. The absence of mercury in working mixture is another advantage of excilamps which is very important from the ecological point of view. The most promising excilamps are those excited by dielectric barrier discharge (DBD) [6]-[8]. DBD are electric discharges between two metallic electrodes, with at least one of them covered by a dielectric material. Excilamps with two barriers have longer lifetimes due to the absence of direct contact between the working gas mixture and the metallic electrodes.

Previous researches have shown that DBD excilamps are particularly efficient when supplied in voltage pulsed mode [7]-[11]. With this supply mode, optimal conditions for supplying excilamps have been found with voltage pulses of some kilovolts applied at frequencies of some tens of kilohertz (around $100 \mathrm{kHz}$ ), with a duty cycle about $1 \%$, featuring very narrow voltage pulses. Nevertheless, the voltage supply mode has appeared to be not really convenient with the intention of implementing an actual control of the UV radiation; this emission has been observed to be correlated with the stiffness of the flanks presented by the voltage pulses, being a property really difficult to control. Our studies are oriented toward disinfection and sterilization [1], [12], as well as dermatologic applications. Keeping this context in mind, a controllable UV emission is a highly desirable feature in these systems.

In this paper, a physical approach, based on finite element simulation, is proposed in Section II, where the correlation between gas current and UV emission is studied and the interest of implementing a pulsed current-source supply for DBD excilamps is established. Section III is devoted to the study of such a pulsed current source; innovative static converter topology, operating principle, design considerations, and actual implementation are presented. Section IV deals with the analysis of the performances obtained by means of this pulsed current source for the control of the UV emission; they confirm the very tight correlation between this emission and the pulsed current injected into the lamp, as well as the capability of the converter to control the UV output power, by means of its degrees of freedom (DOF).

\section{Correlation Between Gas Current and UV EMISSION}

In order to analyze how the current controls the UV emission in an excilamp, we have developed a partial-differentialequation-based (PDE) model [13] for a planar double dielectric 
layer Xenon excilamp. The plasma is assumed homogeneous and side effects around the electrodes are neglected. The computation is consequently performed in one-dimensional, along the axis of the geometry similar to the one presented in [14]. In the modeled system, set up for the purpose of studying the correlation between gas current and UV emission, the thickness of the dielectric layers is $2 \mathrm{~mm}$, the gas gap is $4 \mathrm{~mm}$, and the Xenon filling pressure is $5.33 \times 10^{4} \mathrm{~Pa}$ (400 torr); the geometry of the bulb is symmetrical with respect to the two possible polarities. The model solves the drift-diffusion equations for the species considered in the model coupled to Poisson's equation.

A voltage-supplied DBD (which is the classical approach) is modeled imposing a potential on both outer sides of the dielectrics. This leads to two Dirichlet boundary conditions for Poisson's equation. Usually, one side is grounded and the other is held at the voltage chosen for the modeling.

A current-supplied DBD needs a different approach; it is modeled in grounding one side of the outer surface of a dielectric and imposing the electric field, which is proportional to the time integral of the current, on the outer surface of the other dielectric barrier

$$
\vec{E}\left(x_{0}, t\right)=\frac{1}{\varepsilon} \int_{0}^{t} \vec{j}\left(x_{0}, t\right) d t
$$

where

$\vec{E}\left(x_{0}, t\right)$ is the electric field on the outer dielectric surface,

$\varepsilon \quad$ is the permittivity of the dielectric material, and

$\vec{j}\left(x_{0}, t\right)$ is the current density flowing through the dielectric.

This corresponds to a Neumann boundary condition for the Poisson's equation. The model relies on the local field approximation and consequently the transport coefficients and source terms depend on the electric field. These coefficients and source terms are computed by Bolsig [15]. Once solved, the model can display the evolution of the plasma species density, as well as the electric field, versus time and/or space [16]. From the modeling results, it appears that the mechanism which has the major impact on the development of the discharge is the propagation of the ionization wave, occurring in the neighborhood of the dielectrics in cathode phase. This ionization wave has a strong impact on the current waveform and leads to a massive production of charges, excited species, and particularly excimers [17]. As these latter are responsible for the UV emission, the current waveform is closely related to the time evolution of the UV flux.

When the excilamp is supplied in voltage mode [18], a large part of the voltage drop is transferred on the cathode sheath [19]. As the applied voltage is monotonically evolving, the cathode sheath develops and stores energy. When the voltage drop at the sheath achieves a threshold value, electrons emitted at the cathode have enough energy to ionize the gas, leading to an avalanche and the development of the ionization wave toward the cathode. During this brief phase (some hundreds of nanoseconds), the energy stored in the sheath is released and a part is transferred to excimers, which relax and produce UV. The result is a UV emission peak correlated to a strong current peak in the external circuit due to the sudden collapse of the

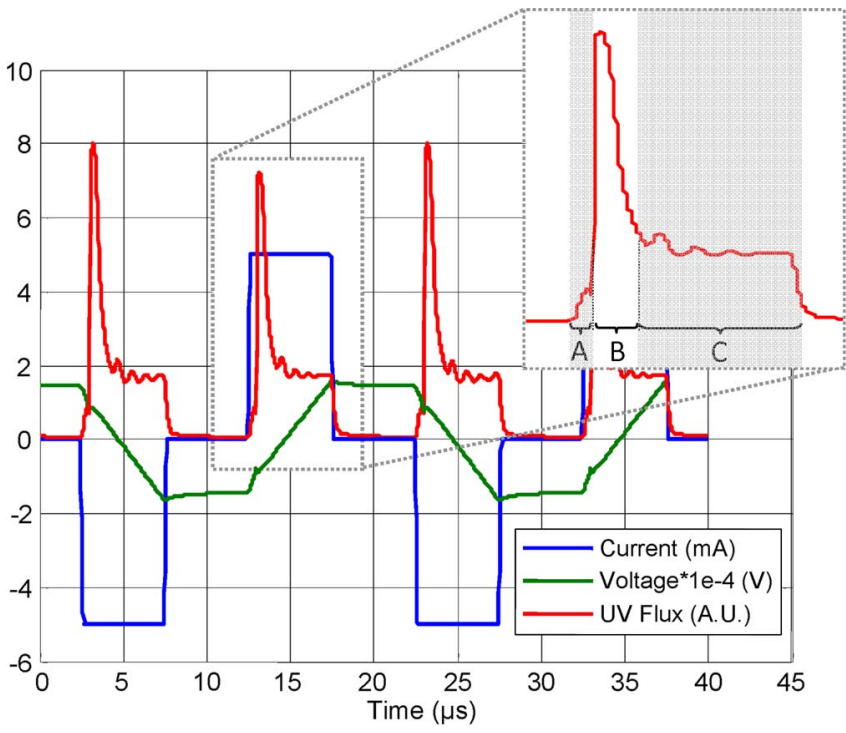

Fig. 1. Time evolution of current and voltage of the lamp (current supply mode) and UV flux of the excilamp at $50 \mathrm{kHz}$.

sheath voltage drop (note that this behavior is associated with a voltage supply; the details concerning the UV emissions can be found in [18]).

When the excilamp is supplied in current mode, the cathode sheath is formed like a current-charged capacitor. During this phase (called phase A, shown on Fig. 1), the imposed current flows mainly in the discharge as a displacement current. Then (phase B), the ionization wave appears (and the associated excimers are created) when the voltage drop at the sheath achieves the threshold. At this moment, the current in the discharge is mainly a conduction current due to the contributions of the imposed current and of the release of the sheath charges. However, if the total current is controlled and sustained (phase C), the ionization wave is then sustained and appears like a settled wave near the cathode. This zone could be considered similar to a negative glow.

The resulting UV flux waveform has a peak due to the release of the sheath energy, followed by a form similar to the imposed current form, if this latter is sustained longer than the peak time width. This can be observed on the simulation results for a $50 \mathrm{kHz}$ square pulsed current wave supplying the modeled excilamp (Fig. 1).

As a result, the UV flux is directly related to the conduction current form. Except during the sheath formation and energy release phases (A and $\mathrm{B}$ ), the conduction current corresponds to the total imposed current. Note that the UV peak (phase B) is associated with a current peak that is internal to the DBD structure; the latter, as a result, does not appear as a current peak in the supply current waveform in Fig. 1.

Consequently, a power supply which is able to execute a current control on an excilamp is also able to achieve a control on its UV flux waveform.

Concerning the lamp voltage waveform of Fig. 1, it should be noted that the gas breakdown occurs when the gas voltage rises to $1800 \mathrm{~V}$. Nonetheless, the lamp voltage is higher at the same moment (as shown in model in Fig. 2, lamp voltage is the sum of gas voltage and dielectric walls voltages). After gas 


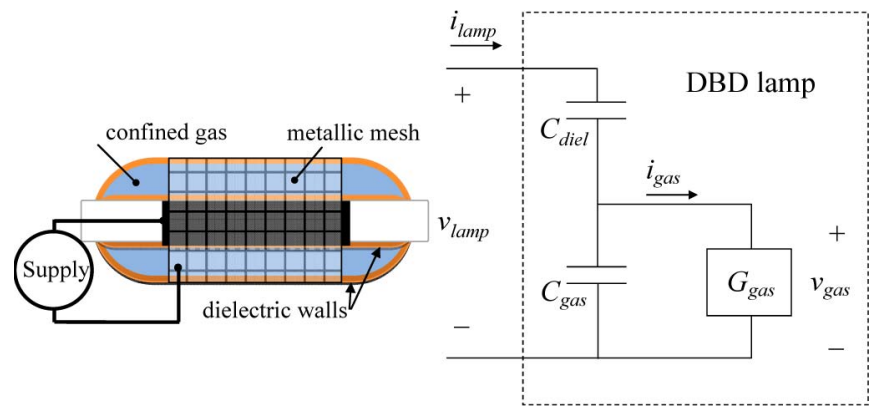

Fig. 2. Geometry and equivalent circuit model of the DBD lamp.

breakdown happens, lamp voltage continues increasing linearly as the dielectric capacitance is supplied by a current source. This is the reason why voltage across the lamp rises to almost $20 \mathrm{kV}$ in Fig. 1.

The aim of the following section is to study a pulsed currentmode supply which will be used to validate the previous reasoning.

\section{Pulsed Current-Mode Power Supply}

The following experiments are accomplished with an axisymmetrical DBD lamp (see Fig. 2). The lamp geometry is approximately $130 \mathrm{~mm}$ in length, with internal and external cylinder radius of $10 \mathrm{~mm}$ and $20 \mathrm{~mm}$, respectively, and barrier thickness of around $1.5 \mathrm{~mm}$. Fused silica is used as the dielectric material and the confined volume is filled with Xenon and $\mathrm{Cl}_{2}$ to produce the $\mathrm{XeCl}$ exciplex $(308 \mathrm{~nm})$. The external electrode, connected to the electrical ground, is conformed by a metallic mesh that wraps the exterior wall, allowing the UV radiation. The internal electrode is a metallic cylinder, which is connected to the power supply output.

\section{A. Specifications for the Pulsed Current-Mode Power Supply}

The waveform of the imposed current, shown in Fig. 1, flowing into the test lamp has been defined a priori. We propose here a reasoned approach for the definition of its characteristics. Concerning the fundamental electrical characteristic of the DBD lamp, the classical equivalent circuit of dielectric barrier discharges is shown in Fig. 2. $C_{\text {diel }}$ is the equivalent series capacitances of the dielectric walls of the lamp; $C_{\text {gas }}$ is the capacitance of the gas gap, which mainly describes the behavior of the latter when the gas voltage $v_{\text {gas }}$ remains under the threshold. When the discharge current appears, the conduction current in the gas is defined by means of the gas conductance $G_{\text {gas }}$.

A complete approach of the modeling of DBD by means of such an equivalent circuit, as well as the delicate issue of the identification of its parameters, is presented in [20]. One of the major benefits of such a predictive model is its ability to calculate the waveforms of nonmeasurable quantities, such as Ggas, igas, vgas, as will be shown later (Section III-D).

Owing to the mainly capacitive nature of the DBD equivalent circuit, a mandatory property of a current source supply will be an average value equal to zero for the lamp " $i_{\text {lamp }}$ " current. This average value has to be evaluated over an interval equal to the operating period of the considered pulsed source.

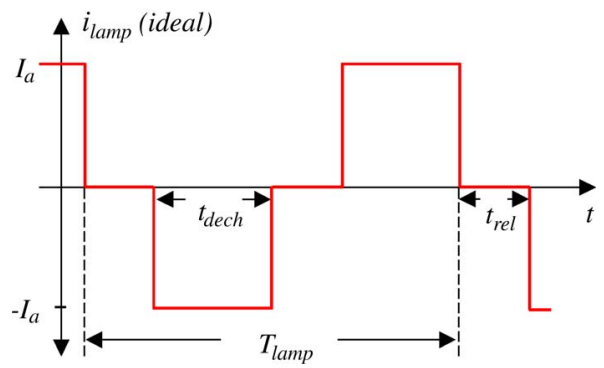

Fig. 3. Idealized current to be injected into the lamp.

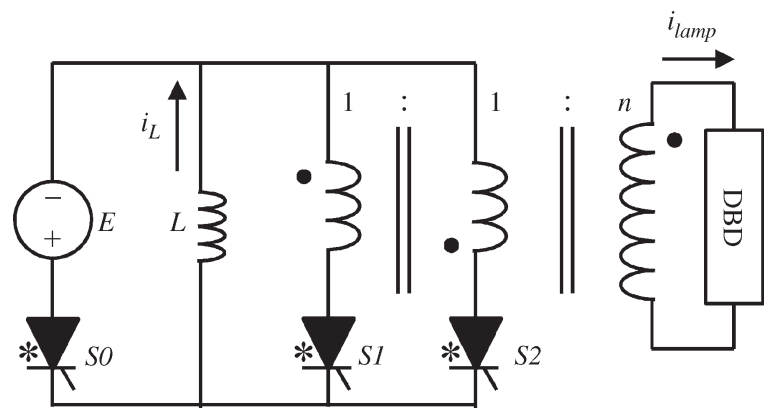

Fig. 4. Pulsed current-mode power converter.

To enable comparisons with the results obtained with a voltage supply, the frequency range of the pulsed current source is chosen similar to the one which is usually selected $(f s$ between $50 \mathrm{kHz}$ and $150 \mathrm{kHz}$ ).

The pattern of the current waveform (Fig. 3) is chosen similar to the one shown in the simulation of Fig. 1; three parameters are used to define it:

1) the magnitude of the current pulses $I_{a}$;

2) the duration of the current pulses tdech;

3) the duration of the relaxing time interval trel during which the lamp current remains zero (this quantity, in conjunction with the previous one defines the value of the operating period Tlamp).

Finally, the power transferred to the lamp by the pulsed current supply is taken from a de voltage stage (typically $100 \mathrm{~V}$ ).

\section{B. Power Supply Topology, Operating Principle, and Degrees of Freedom}

1) Topology: A static converter circuit that complies with the current-mode idea and the specifications detailed in Section I was developed in [17], [21]. This topology is synthesized starting from a buck-boost converter operating in discontinuous current mode (DCM), cascaded with an H-bridge and a stepup transformer. The H-bridge is inserted to achieve the periodic inversion of the lamp current direction. The transformer is used to adjust the voltage in the lamp to the semiconductor devices range. After the simplification of the structure (elimination of redundant switches), the final topology is shown in Fig. 4.

2) Operating Sequences: Fig. 5 shows the idealized expected waveforms (current in the $L$ inductance $i_{L}$ and current in the lamp $i_{l a m p}$ ). These plots are obtained with a circuit simulation program [22], [23]; the step-up transformer is 


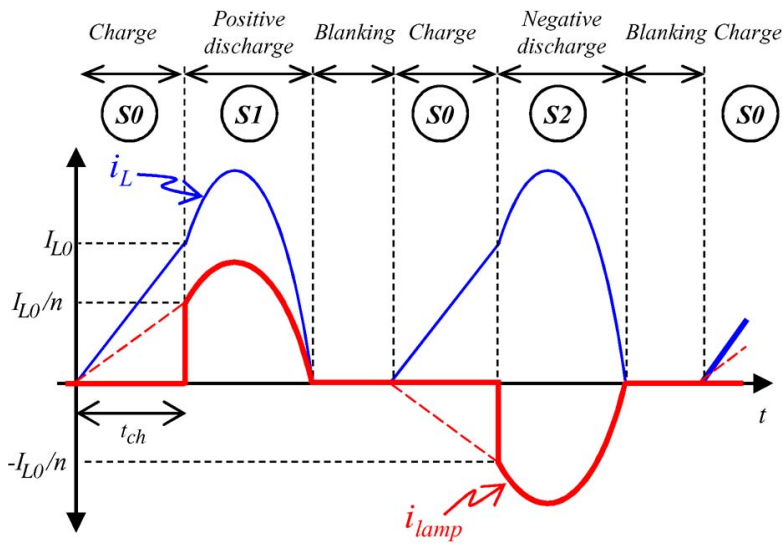

Fig. 5. Main waveforms of the pulsed current-mode power converter. Each sequence is represented with its corresponding ON state switch (see Fig. 6).

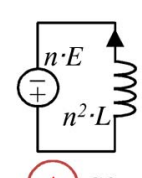

(A) $s 0$

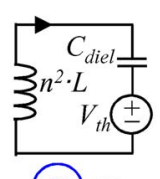

(B) $\mathrm{S1}$

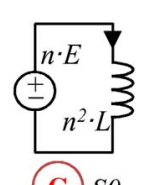

C) $\mathrm{SO}$

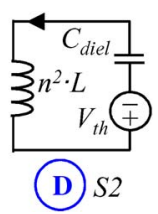

D) $s 2$
Fig. 6. Operating sequences of the pulsed current-mode supply (as seen from the secondary winding of the transformer).

supposed ideal (1:n ratio) and the lamp is sketched, according to the characteristic which will be presented in Fig 8, as a $\pm V_{t h}$ (the threshold voltage $V t h$ is around $1800 \mathrm{~V}$ ) voltage source in series with the dielectric capacitor $C_{\text {diel }}$.

The operating sequences, according to the states of the switches of the converter are shown in Fig. 6.

During sequences (A) and (C), the energy is stored in the $L$ inductance; as the current in the inductance starts from 0 at the beginning of the sequences (in agreement with DCM mode), this energy is controlled by the duration of these sequences (see (3) below).

This stored energy is transferred through the transformer into the lamp during the oscillating sequences (B) and (D), involving $L$ and $C$ diel.

3) Degrees of Freedom (DOF): A very important feature of this converter is shown in Fig. 5; as stated in (2) and (4), $t_{\text {charge, }}$ the duration of sequences (A) and (C) - energy stored in the $L$ inductance-permits to control the amount of energy $E_{\text {pulse }}$ which is injected into the lamp during each half period during sequences (B) or (D). In (2) and (3), $E$ denotes the DC voltage source (see Fig. 4) and $I_{L 0}$ denotes the current in the $L$ inductor at the end of sequences (A) and (C).

The duration of the sequences (B) and (D) $t_{\text {discharge }}$ is defined by the values of $C_{\text {diel }}, L, n$ (step-up ratio of the transformer), and $I_{L 0}$ [24]; they naturally finish when the $i_{L}$ current matches a zero value (spontaneous turn-off of the thyristors-like switches, as will be detailed in next section-see Section III-C1).

A blanking time interval $\left(t_{\text {blanking }}\right)$, added once, between sequences (B) and (C) and then between (D) and (A), is introduced to adjust the relaxation time interval between two current pulses in the lamp [as stated with (5)].
The pulse energy $E_{\text {pulse }}$, combined with the operating frequency $f_{s}$, defines the average power $P_{\text {lamp }}$ transferred to the lamp [see (4)].

$$
\begin{aligned}
I_{L 0} & =E . t_{\text {charge }} / L \\
E_{\text {pulse }} & =1 / 2 \cdot L \cdot I_{L 0}^{2}=E^{2} \cdot t_{\text {charge }}^{2} / 2 L \\
P_{\text {lamp }} & =2 . f_{s} \cdot E_{\text {pulse }}=2 \cdot f_{s} \cdot\left(\frac{1}{2} L \cdot I_{L 0}^{2}\right) \\
T & =\left(t_{\text {charge }}+t_{\text {discharge }}+t_{\text {blanking }}\right) \cdot 2=1 / f_{s}
\end{aligned}
$$

As a conclusion, concerning the control of the pulsed currentmode supply, different variables are available for this purpose; they all rely on an accurate time management of the sequences:

1) two independent quantities (pulse energy $E_{\text {pulse }}$ and operating frequency) can be used to define the average power transferred to the lamp;

2) the pulse energy $E_{\text {pulse }}$ is directly controllable by means of the duration of sequences (A) and (C) $t_{\text {charge }}$;

3 ) the operating period is defined by $t_{\text {charge }}$ together with $t_{\text {blanking. }}$

Note that the control stated above is valid for $E_{\text {pulse }}$ large enough to breakdown the gas during each polarity change. Consequently, the voltage across the lamp must comply with (6) during the most part of sequences (B) and (D).

$$
\left|v_{\text {lamp }}\right|>V_{t h} \cdot\left(\frac{C_{g a s}+C_{d i e l}}{C_{\text {diel }}}\right)
$$

\section{Design of the Pulsed Current-Mode Power Supply}

Concerning the design of such a pulsed current mode supply, one should mention three important issues which are considered below:

1) dedicated power switches;

2) design of the step up transformer;

3) time management.

1) Thyristor-Like Switches: The three switches of the converter (Fig. 4) require thyristor-like operating characteristics: unidirectional current in ON state and bidirectional voltage in OFF state, with controlled turn-on under positive voltage and spontaneous turn-off at zero current crossing. The usual operating frequencies of classical thyristor devices are not compatible with the frequency expected in the considered application (some kilohertz).

Thus, a synthesized function based on a power MOSFET, in series with a high voltage fast diode, associated with an electronic management circuit (Fig. 7) has been particularly studied and designed [21].

2) Step-Up Transformer: The design of the step-up transformer, which is a critical point for the setup of such a supply, is a very important issue; indeed, the parasitic parameters of the windings (particularly the high voltage one) have a critical effect on the quality of the waveforms and of the operating conditions.

The magnetizing inductance must have a value large enough to avoid current flow through the lamp during sequences (A) and $(\mathrm{C})$. 


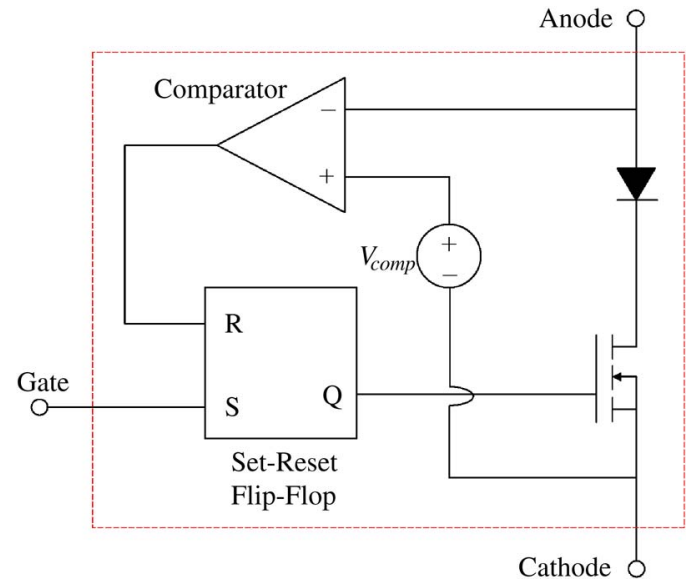

Fig. 7. High frequency thyristor-like structure.

TABLE I

ELECTRIC CHARACTERISTICS OF THE SUPPLY

\begin{tabular}{|c|c|}
\hline$f_{S}$ (operating frequency) & $50 \mathrm{kHz}$ \\
\hline$L$ (primary inductor) & $160 \mu \mathrm{H}$ \\
\hline$N$ (step-up transformer ratio) & 12 \\
\hline$E$ (voltage supply) & $150 \mathrm{~V}$ \\
\hline Lo (current at end of seq. $(A)$ or $(C))$ & $\leq 3 \mathrm{~A}$ \\
\hline Max. pulse energy (at $50 \mathrm{kHz})$ & $720 \mu \mathrm{J}$ \\
\hline Electric power (measured in the lamp) & $5-40 \mathrm{~W}$ \\
\hline$\eta$ (measured electric efficiency) & $\sim 70 \%$ \\
\hline
\end{tabular}

Leakage inductances should be minimized to avoid high frequency oscillations during sequences (B) and (D).

As for the capacitance of the secondary winding, it derives a percentage of the current in the lamp and should be minimized as well.

3) Accurate Management of the Firing Events: In the experimental setup, the previously mentioned DOF, available for the control of the power transfers (Section III-B3), are managed by means of a DSP-FPGA-based control unit. This equipment accurately defines all the events through the firing orders of each power switch and offers possible transient analysis and time domain measurements.

\section{Implementation and Experimental Results}

A prototype of the pulsed current-mode supply has been implemented; the main electric characteristics are summarized in Table I.

Fig. 8 shows the current measured in the $L$ inductance and the current in the lamp $i_{\text {lamp }}$. These waveforms appear to be very similar to the theoretical ones; higher frequency oscillations, which appear on the $i_{\text {lamp }}$ signal, are caused by the mentioned parasitic elements of the step-up transformer.

Using the model described in Section I, nonmeasurable quantities are also calculable; the computed current flowing through the gas $i_{\text {gas }}$ is presented. The latter appears to be very similar to the $i_{\text {lamp }}$ current, except at the beginning of the energy transfer sequence, when the current injected into the lamp flows mainly in the discharge as a displacement current and is used to modify

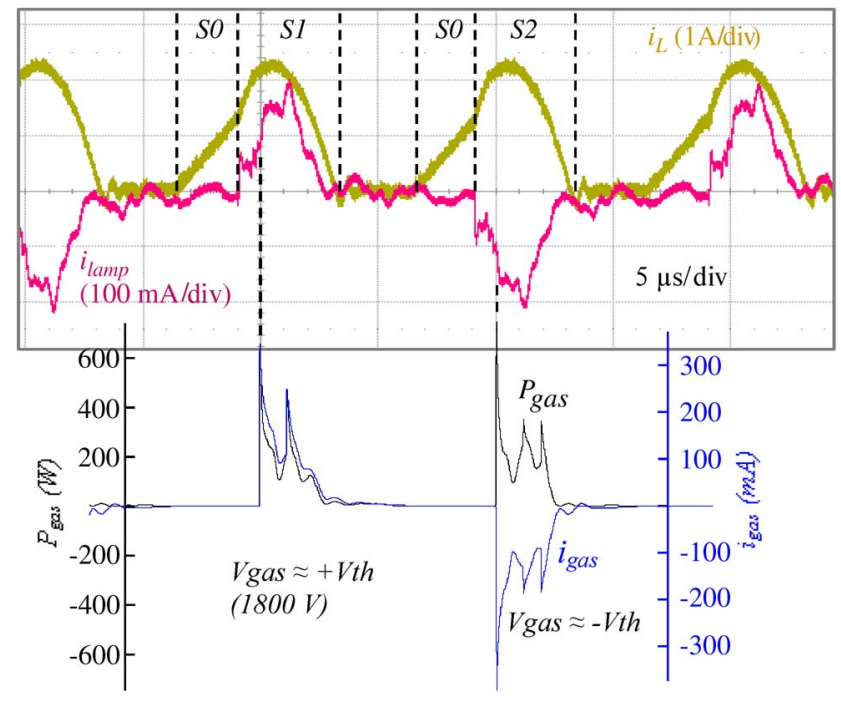

Fig. 8. Measured currents: (brown) $i_{L}$ and (red) $i_{\text {lamp }}$ - computed current (blue) $i_{\text {gas }}$ and power (black) $P_{\text {gas }}$.

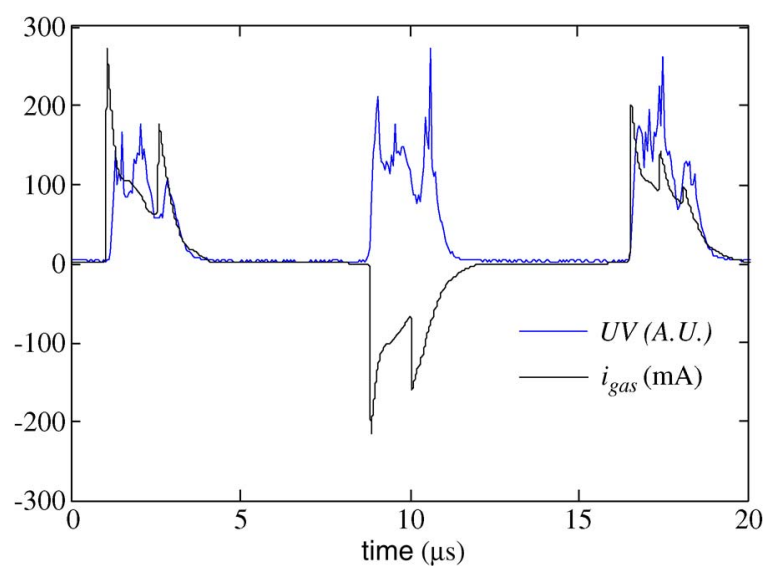

Fig. 9. Measured instantaneous UV power (blue) compared to the (black) computed $i_{\text {gas }}$ current.

the charge of the $C_{\text {gas }}$ capacitor, according to the polarity of the discharge. The instantaneous power transferred to the gas $P_{\text {gas }}$ is also shown. One can notice that the waveforms of $i_{\text {gas }}$ and $P_{\text {gas }}$ are very similar, indicating that the gas voltage is almost constant. This last point confirms the hypothesis which has been stated in previous sections (see Section III-B2), concerning the behavior of the discharge in ON state, and defines the used value of the $V_{t h}$ voltage $\left(V_{t h} \pm 1800 \mathrm{~V}\right)$.

\section{UV RADIATION CONTROL}

Associated to the power supply, an optical apparatus has been developed, which offers time-resolved (with synchronization on the control signals of the switches of the power supply) and averaged measurements of the produced light, both in the visible and UV domains. The experimental system used in Fig. 9 is based on a high-speed CCD Roper Scientific PI-MAX camera, with a bandpass UV filter. For Fig. 10, a H25 Jobin-Yvon monochromator was used instead of the filter. The controller of the camera handles the synchronization of the $30 \mathrm{~ns}$ acquisitions with the firing logical signals of the 


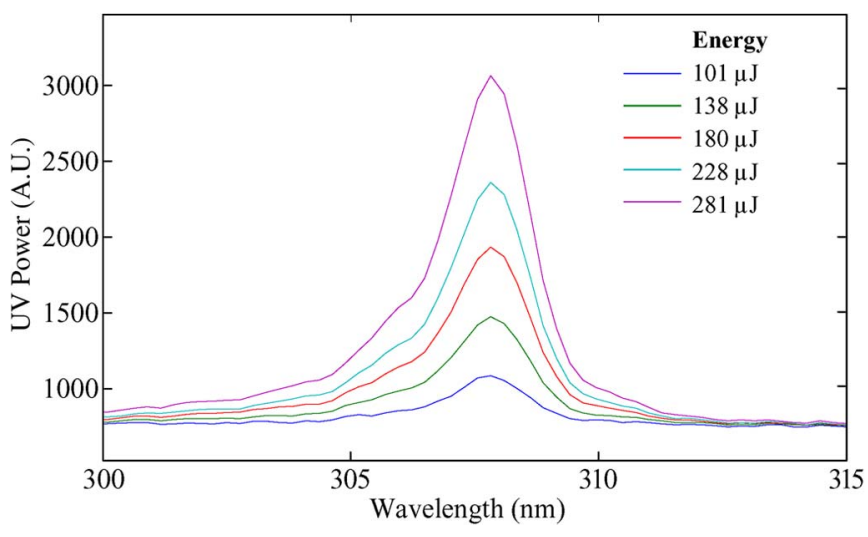

Fig. 10. Power distribution of the UV emission for different levels of pulse energy (operating frequency of the supply: $50 \mathrm{kHz}$ ).

excilamp power supply. For Fig. 12, a UV photodiode with a fast amplifier was used. The rising time of the system is lower than $100 \mathrm{~ns}$. The photodiode method is simpler for realtime measurement. Nevertheless, it presents electromagnetic interference perturbations in the waveform due to the switching of the converter. For this reason, the pure optical system is used in Fig. 9.

\section{A. Correlation Between Gas Current and UV Radiation}

The comparison between the shapes of the instantaneous UV power and the computed $i_{\text {gas }}$ current is proposed on Fig. 9.

Due to the synchronization between the power supply and the optical measurements apparatus, the similarity of the waveforms is undoubtedly stated. This point confirms the physical reasoning which has been developed in Section II.

Several similar measurements, with different $i_{\text {gas }}$ pulses durations, have been realized and have given identical conclusions: the shape of the UV emission is very tightly correlated to the $i_{\text {gas }}$ current in the gas. One should remember that the latter is not directly controllable; the DOFs of the supply allow the control of the $i_{l a m p}$ current in the lamp, which appears to be identical to $i_{\text {gas }}$ as soon as the discharge is in ON state and the voltage across the gap capacitor $C_{\text {gas }}$ has reached the $V_{t h}$ threshold voltage. Note that the gas current is computed with the model of Fig. 2 using the experimental lamp current as input. That explains the pulse-to-pulse fluctuation in the gas current in Fig. 9.

\section{B. Stability of the UV Emission}

The quality of the produced UV has been checked with different levels of energy injection (controlled by means of the $t_{\text {charge }}$ duration); Fig. 10 proves that the spectral quality of the radiation of the lamp is not affected by the transferred power.

The power distribution remains clearly centered on $308 \mathrm{~nm}$ (which is the specific wavelength for $\mathrm{XeCl}$ lamps), whatever the pulse energy level is.

\section{Time Domain Behavior of the Whole System}

By means of the $t_{\text {charge }}$ DOF of the supply, which controls the energy of the current pulses, a current step has been realized

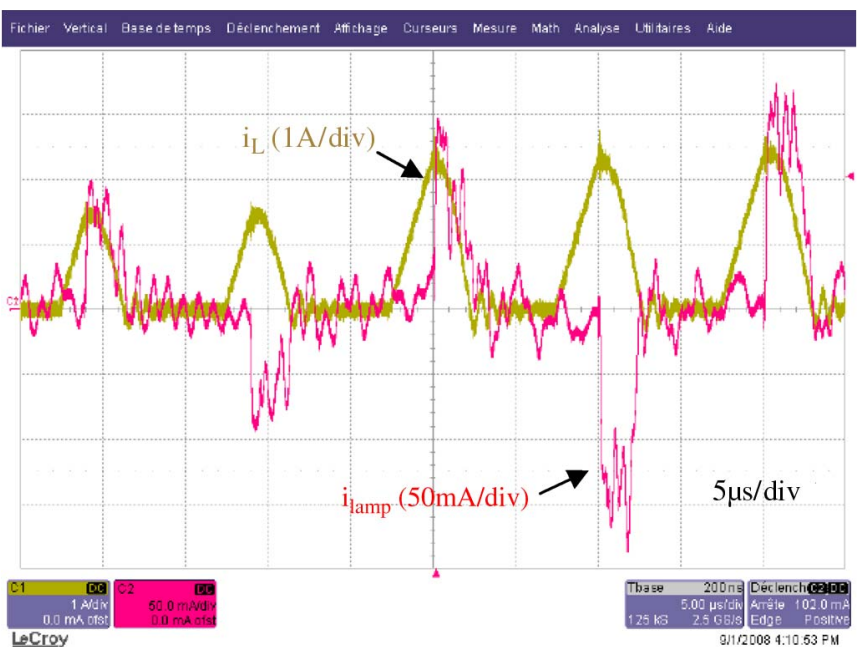

Fig. 11. Instantaneous control of the $i_{l a m p}$ current following a pulse energy step $\left(i_{L}\right.$ is the current of the inductance which controls the pulses energy).

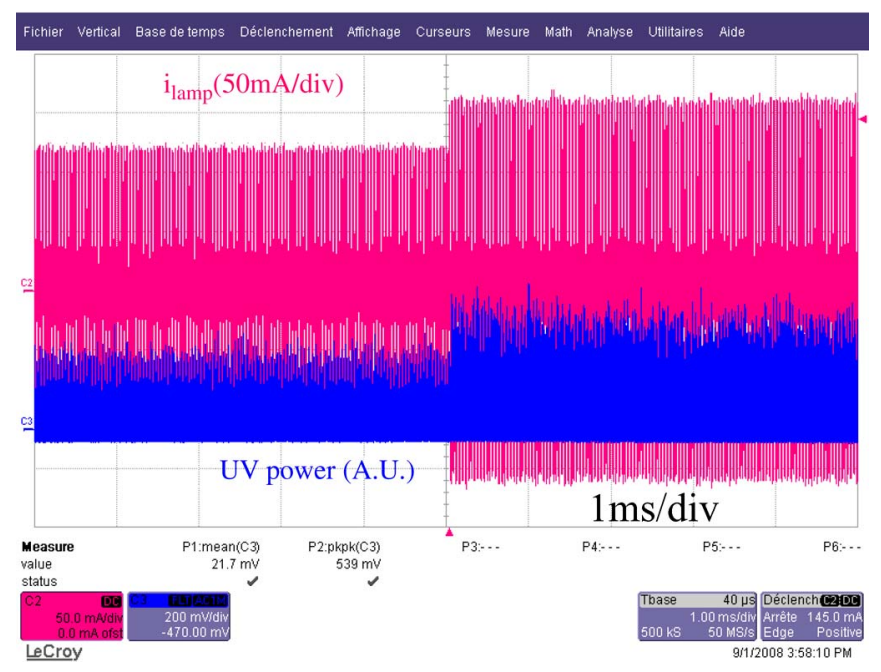

Fig. 12. UV production controlled by the power supply.

[see (2)]. This event, as shown in Fig. 11, is immediately followed by a similar current step in the $i_{\text {lamp }}$ current.

Concerning the produced $\mathrm{UV}$, any change in the pulse current is immediately followed by the same change on the UV emission; as it appears in Fig. 12, the magnitude of the UV emission is directly controlled by the injected lamp current (in Fig. 12, the step response of the system is highlighted). The timescale range concerned by this last statement starts from at least half the period of the supply.

\section{Output Characteristics of the Pulsed Current-Source Supply}

Considering the mean values of the UV power (measured with a 308-nm radiometer), the DOFs of the supply have been used to study the correlation between the relative UV power and the pulses energy for several operating frequencies.

The plots of Fig. 13 show both electrical power injected into the lamp and UV emission power, versus the current pulses energy, for different operating frequencies. 

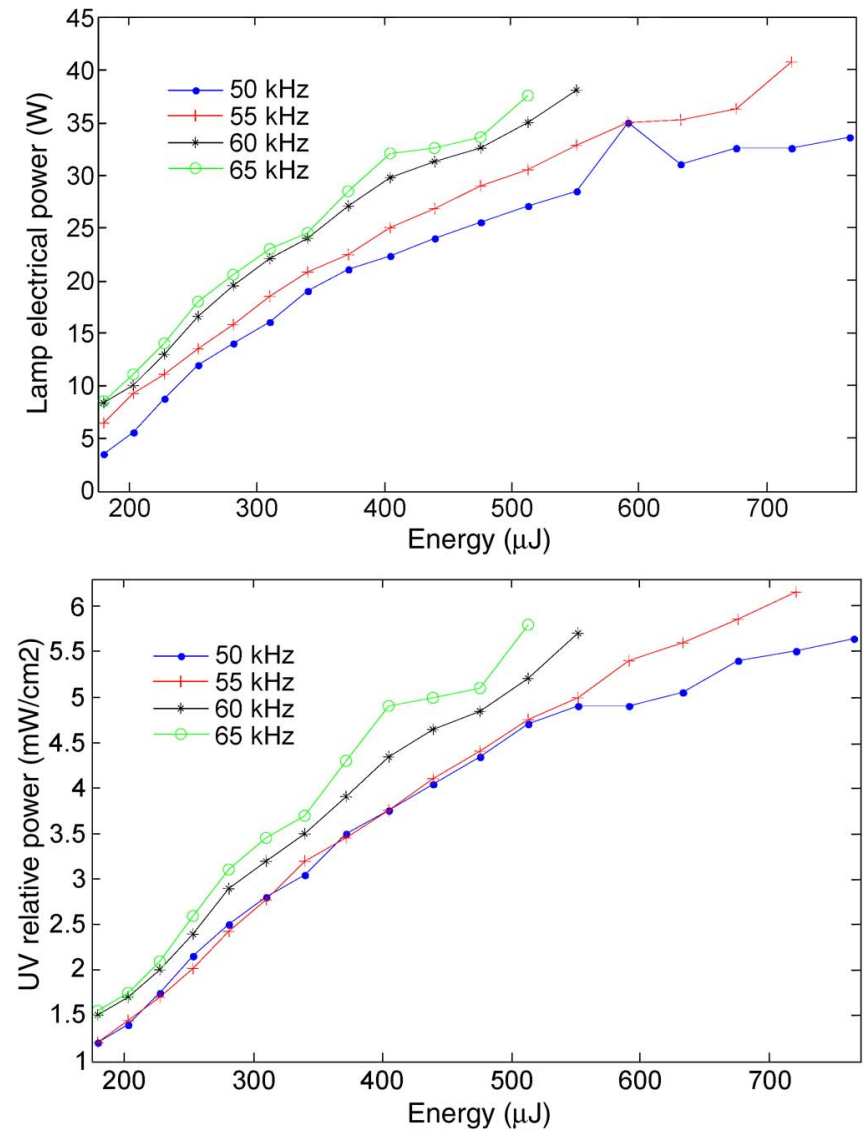

Fig. 13. (a) Electrical power transferred to the lamp and (b) UV emission power, both versus pulse energy.

According to (4), for a given pulses energy, the transferred electrical power should increase linearly with the operating frequency; the plots of Fig. 13(a) should be homothetically spaced. The actual organization of these plots let us conclude that the electrical efficiency of the supply decreases when the frequency reaches a $65 \mathrm{kHz}$ value (the design of the latter has been realized for a nominal $50 \mathrm{kHz}$ frequency). This reduction of electrical efficiency can be explained as the switching losses and the transformer losses increase with the frequency. Particular care must be taken for lower frequencies if the same average power is desired, as the inductance core could saturate for high energy levels.

Concerning the light emission, Fig. 13(b) shows the UV power increase:

1) with the pulse energy controlled by means of the $t_{\text {charge }}$ duration, see (3);

2) for a given level of pulse energy, with the operating frequency, see (4).

One can notice that the lower curve at $50 \mathrm{kHz}$ remains very near to the one at $55 \mathrm{kHz}$. This can be interpreted as better conversion from electrical to optical power (higher efficiency) of the lamp at $50 \mathrm{kHz}$. Actually, at $50 \mathrm{kHz}$ the electrical to optical power efficiency is nearly $15 \%$ better than for the other frequencies $(55,60$, and $65 \mathrm{kHz})$.

These facts also suggest using the pulsed current-mode power supply to identify the optimal operating frequency of the lamp.

\section{CONCLUSION}

The concept of a pulsed current-mode power supply for DBD excilamps has been introduced on the basis of physical considerations concerning the correlation between the UV emission and the electrical quantities associated with the lamp.

According to the conclusions of this first step, specific topologies for static converters implementing the pulsed current mode principle have been proposed and experimental setup has been designed.

A UV optical measurement apparatus, synchronized with the power supply, has been associated with the experimental setup; it has highlighted the fact that the UV production is directly controlled by the current which actually flows into the gas-this non-observable current is controllable by means of the current which is injected in the lamp.

The proposed solutions have shown the capability to control, by means of its DOFs, the energy of each current pulse injected into the lamp (at each half operating period), as well as the mean value of the power transferred from the supply to the lamp.

\section{ACKNOWLEDGMENT}

The authors would like to thank Dermoptics (Quantel Group) for providing their patented lamp.

\section{REFERENCES}

[1] M. V. Erofeev, I. E. Kieft, E. A. Sosnin, and E. Stoffels, "UV excimer lamp irradiation of fibroblasts: The influence on antioxidant homeostasis," IEEE Trans. Plasma Sci., vol. 34, no. 4, pp. 1359-1364, Aug. 2006.

[2] E. A. Sosnin, S. M. Avdeev, E. A. Kuznetzova, and L. V. Lavrent'eva, "A bactericidal barrier-discharge $\mathrm{KrBr}$ excilamp," Instrum. Exp. Tech., vol. 48, no. 5, pp. 663-666, Sep. 2005.

[3] E. A. Sosnin, T. Oppenländer, and V. F. Tarasenko, "Applications of capacitive and barrier discharge excilamps in photoscience," J. Photochem. Photobiol. C: Rev., vol. 7, no. 4, pp. 145-163, Dec. 2006.

[4] E. A. Sosnin, I. V. Sokolova, and V. F. Tarasenko, "Development and applications of novel UV and VUV excimer and exciplex lamps for the experiments in photochemistry," in Photochemistry Research Progress, A. Sanchez and S. J. Gutierrez, Eds. Commack, NY: Nova, 2008.

[5] I. V. Sokolova, O. N. Chaikovskaya, V. A. Svetlichnyi, R. T. Kuznetsova, T. N. Kopylova, G. V. Maier, E. A. Sosnin, E. A. Lipatov, and V. F. Tarasenko, "Photo transformations of phenols in aqueous solutions under different excitation modes," High Energy Chem., vol. 36, no. 4, pp. 272-275, Jul. 2002.

[6] U. Kogelschatz, "Dielectric-barrier discharges: Their history, discharge physics, and industrial applications," Plasma Chem. Plasma Process., vol. 23, no. 1, pp. 1-46, Mar. 2003.

[7] M. I. Lomaev, E. A. Sosnin, V. F. Tarasenko, D. V. Shits, V. S. Skakun, M. V. Erofeev, and A. A. Lisenko, "Capacitive and barrier discharge excilamps and their applications (review)," Instrum. Exp. Tech., vol. 49, no. 5, pp. 595-616, Oct. 2006.

[8] B. Rahmani, S. Bhosle, and G. Zissis, "Dielectric-barrier-discharge excilamp in mixtures of Krypton and molecular chlorine," IEEE Trans. Plasma Sci., vol. 37, no. 4, pp. 546-550, Apr. 2009.

[9] R. P. Mildren and R. J. Carman, "Enhanced performance of a dielectric barrier discharge lamp using short-pulsed excitation," J. Phys. D, Appl. Phys., vol. 34, no. 1, pp. L1-L6, Jan. 2001.

[10] R. P. Mildren, R. J. Carman, and I. S. Falconer, "Visible and VUV emission from a Xenon dielectric barrier discharge using pulsed and sinusoidal voltage excitation waveforms," IEEE Trans. Plasma Sci., vol. 30, no. 1, pp. 192-193, Feb. 2002.

[11] R. J. Carman and R. P. Mildren, "Computer modelling of a short-pulse excited dielectric barrier discharge Xenon excimer lamp (172 nm)," J. Phys. D, Appl. Phys., vol. 36, no. 1, pp. 19-33, Jan. 2003.

[12] M. Laroussi, F. C. Dobbs, Z. Wei, M. A. Doblin, L. G. Ball, K. R. Moreira, F. F. Dyer, and J. P. Richardson, "Decontamination of water by excimer UV radiation," IEEE Trans. Plasma Sci., vol. 30, no. 4, pp. 1501-1503, Aug. 2002. 
[13] S. Bhosle, G. Zissis, J. J. Damelincourt, and A. Capdevila, "A new approach for boundary conditions in dielectric barrier discharge modeling," presented at the Gas Discharge, Xian, China, 2006.

[14] A. Oda, Y. Sakai, H. Akashi, and H. Sugawara, "One-dimensional modelling of low frequency and high-pressure Xe barrier discharges for the design of excimer lamps," J. Phys. D, Appl. Phys., vol. 32, no. 21, pp. 27262736, Nov. 1999.

[15] Laplace Laboratory and Kinema Software, 1995. [Online]. Available: http://www.Laplace.univ-tlse.fr/Download/

[16] S. Bhosle, R. Diez, H. Piquet, D. Le Thanh, B. Rahmani, and D. Buso, "Modeling of a dielectric barrier discharge lamp for UV production," in Proc. COMSOL Multiphysics User's Conf., Hannover, Germany, 2008.

[17] H. Piquet, S. Bhosle, R. Diez, A. Toumi, and G. Zissis, "Innovative power supply concepts for DBD excilamps," in Proc. SPIE, 2007, vol. 6938, p. 693810

[18] A. Oda, H. Sugawara, Y. Sakai, and H. Akashi, "Estimation of the light output power and efficiency of Xe barrier discharge excimer lamps using a one-dimensional fluid model for various voltage waveforms," J. Phys. D, Appl. Phys., vol. 33, no. 12, pp. 1507-1513, Jun. 2000.

[19] S. Bhosle, G. Zissis, J. J. Damelincourt, A. Capdevila, K. Gupta, F. P. Dawson, and V. F. Tarasenko, "Implementation of an efficiency indicator in an electrical modeling of a Dielectric Barrier Discharge Lamp," in Conf. Rec. 41st IEEE/IAS Annu. Meeting, Tampa, FL, Oct. 8-12, 2006, pp. 1784-1790.

[20] R. Díez, J.-P. Salanne, H. Piquet, S. Bhosle, and G. Zissis, "Predictive model of a DBD lamp for power supply design and method for the automatic identification of its parameters," Eur. Phys. J. Appl. Phys., vol. 37, no. 3, pp. 307-313, Mar. 2007.

[21] R. Diez, H. Piquet, S. Bhosle, and J.-M. Blaquiere, "Current mode converter for dielectric barrier discharge lamp," in Proc. IEEE Power Electron. Spec. Conf., Jun. 2008, pp. 2485-2491.

[22] PSIM User's Guide, Powersim Inc., Woburn, MA, 2005. [Online]. Available: http://www.powersimtech.com

[23] Saber MAST Language Reference, Synopsys, Mountain View, CA, 2005. http://www.synopsys.com

[24] R. Díez, H. Piquet, S. Bhosle, J.-M. Blaquière, and N. Roux, "Design of a current converter for the study of the UV emission in DBD excilamps," in Proc. IEEE-ISIE, 2008, vol. 1, pp. 62-67.

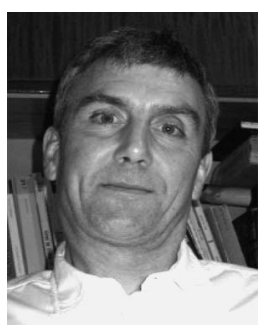

Hubert Piquet received the degree in applied physics from the Ecole Normale Supérieure de Cachan, Cachan, France, in 1984 and the Ph.D. degree in electrical engineering from the Institut $\mathrm{Na}-$ tional Polytechnique de Toulouse, Toulouse, France, in 1990.

$\mathrm{He}$ is currently a Professor at the ENSEEIHT Ing. School, Toulouse, where he teaches Power Electronics. His research activity takes place in the LAPLACE laboratory (Energy Conversion and Plasma Lab., Toulouse, France). His main research interests include quality and stability in embedded networks and power supplies for the electrical discharge applications.

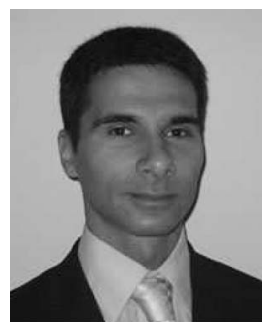

Sounil Bhosle (M'00) was born in Poitiers, France, in 1972. He received the degree in physics from the Poitiers University, Poitiers, France, in 1996 and the Master and Ph.D. degrees on plasma science from the Toulouse 3 University, Toulouse, France, in 2001 and 2006, respectively.

$\mathrm{He}$ is a specialist of dielectric barrier discharge lamps. From 1997 to 2009, he occupied a position in the Laboratory of Plasma and Conversion of Energy (LAPLACE), Toulouse, France. He is now a Research and Development Engineer in LED Engineering Development in Toulouse. He is Vice-Chair of the Industrial Lighting and Displays Committee of the IEEE Industry Application Society. He has presented more than 20 papers in international journals and conferences.

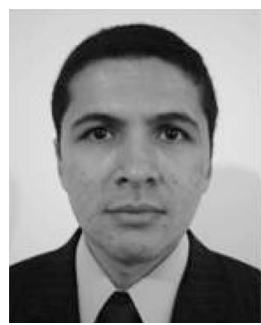

Rafael Diez received the degree in electronic engineering from the Pontificia Universidad Javeriana, Bogotá, Colombia, in 2001, the Master's degree in microelectronics from the Universite Paul Sabatier de Toulouse, Toulouse, France, in 2005, and the $\mathrm{Ph} . \mathrm{D}$. degree in electrical engineering from the Institut National Polytechnique de Toulouse, Toulouse, France, in 2008.

$\mathrm{He}$ is currently an Assistant Professor with the Department of Electronics at the Pontificia Universidad Javeriana. His main research interest is the development of power converters for electric discharges.

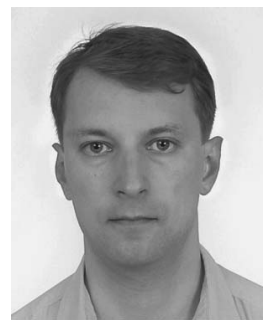

Lasers.
Michael V. Erofeev received the M.S. and Ph.D. degrees in optics from the Tomsk State University, Tomsk, Russia, in 1997 and 2001, respectively.

Since 1997, he has been with the Institute of High Current Electronics, Siberian Branch of Russian Academy of Sciences, Tomsk, Russia, where he is a Research Officer. His research interests are in plasma science, pulsed power, sources of UV radiation and their application in photochemistry and photomedicine. He is also a Scientific Secretary for International Conference on Atomic and Molecular Pulsed 